\title{
Determinants of Prognosis in Triple-Negative Breast Cancer: Report from a Large Breast Cancer Registry
}

\author{
Sedigheh Tahmasebi, MD ${ }^{1}$; Ali Mosa Jafar Almayali, MD²; Peyman Arasteh, MD ${ }^{1}$; Majid Akrami, MD ${ }^{1 *}$; Vahid Zangouri, MD ${ }^{1,3}$; \\ Payam Arasteh, MD ${ }^{1,4}$; Seyed Morteza Hosseini, MD; Aida Salehi Nobandegani, MD¹; Azam Asgari, MD¹; Erfan Sadeghi, PhD ${ }^{5,6}$; \\ Leila Zahiri, $\mathrm{MD}^{7}$; Abdolrasoul Talei, $\mathrm{MD}^{1}$ \\ ${ }^{1}$ MBreast Diseases Research Center, Shiraz University of Medical Sciences, Shiraz, Iran \\ ${ }^{2}$ Department of Surgery, Karbala University of Medical Sciences, Karbala, Iraq \\ ${ }^{3}$ Surgical Oncology Division, General Surgery Department, Shiraz University of Medical Sciences, Shiraz, Iran \\ ${ }^{4}$ Department of Foreign Languages and Linguistics, Shiraz University, Shiraz, Fars, Iran \\ ${ }^{5}$ Non-communicable Disease Research Center, Fasa University of Medical Sciences, Fasa, Iran \\ ${ }^{6}$ Department of Biostatistics and Epidemiology, Faculty of Health, Isfahan University of Medical Sciences, Isfahan, Iran \\ ${ }^{7}$ Department of Internal Medicine, Shiraz University of Medical Science, Shiraz, Iran
}

\begin{abstract}
Background: The outcome of patients with triple-negative breast cancer (TNBC) is highly dependent on demographic factors and ethnicity. We aimed to evaluate the clinicopathological determinants of prognosis among women with TNBC using data from one of the largest breast cancer $(\mathrm{BC})$ registries.

Methods: A total of 6145 patients with BC from our referral center were evaluated from 1995 to 2018, among whom 523 had TNBC. The baseline, menstrual and reproductive, treatment and pathology related characteristics were evaluated.

Results: Among TNBC patients, the rate of stage 3 and 4 BC $(29.9 \%$ vs. $14.4 \%$ and $7.8 \%$ vs. $0 \%$ for stage 3 and 4 , respectively; $P<0.001)$, invasive ductal carcinoma $(90.7 \%$ vs. $75.6 \% ; P=0.004)$, nodal involvement $(46.7 \%$ vs. $33.4 \% ; P=0.026)$, mastectomy $(57.3 \%$ vs. $37.8 \% ; P=0.001)$ and axillary node dissection $(76.7 \%$ vs. $59.8 \% ; P=0.019)$ was significantly higher in the group that developed recurrence.

Disease-free-survival was $80.6 \%$ (157.76 \pm 9.48 months) and overall-survival was $90.1 \%$ (182.73 \pm 3.28 months). For death, stage $3 \mathrm{BC}$ (compared to stages 0 and 1 as base) showed a higher risk of earlier death (adjusted HR: 4.191, 95\% $\mathrm{Cl}=1.392-12.621$; $P=0.011$ ). For recurrence, stage $3 \mathrm{BC}$ (adjusted HR: $1.044,95 \% \mathrm{Cl}=1.209-6.673 ; P=0.017$ ) (compared to stages 0 and 1 as base) showed significantly higher risk for developing earlier recurrence. Moreover, those who had invasive ductal carcinoma (compared to other types of $\mathrm{BCs}$ ) had a higher risk for developing earlier recurrence (adjusted $\mathrm{HR}: 3.307,95 \% \mathrm{Cl}=1.191-0.724 ; P=0.012$ ). Conclusion: BC stage plays a significant role in both earlier recurrence and earlier mortality among patients with TNBC.

Keywords: Breast cancer, Iran, Prognosis, Triple negative breast neoplasms

Cite this article as: Tahmasebi S, Almayali AMJ, Arasteh P, Akrami M, Zangouri V, Arasteh P, et al. Determinants of prognosis in triple-negative breast cancer: report from a large breast cancer registry. Arch Iran Med. 2021;24(4):280-288. doi: 10.34172/ aim.2021.39
\end{abstract}

Received: March 9, 2020, Accepted: August 2, 2020, ePublished: April 1, 2021

\section{Introduction}

Triple-negative breast cancer (TNBC) represents a subgroup of tumors that mainly lack specific surface antigens including hormone receptors (which includes estrogen $[\mathrm{ER}]$ and progesterone receptors $[\mathrm{PR}]$ ) and the HER-2/neu or the human epidermal growth factor receptor 2. ${ }^{1}$ TNBC comprises an estimated 10\%-20\% of all newly diagnosed early breast cancers (BC) and is often considered a basal-like BC. ${ }^{2,3}$ Literature has shown that patients with TNBC have an overall worse clinical outcome and a higher recurrence rate compared to $\mathrm{BC}$ patients who are hormone receptors positive. ${ }^{4,5}$ TNBC patients show a unique pattern of recurrence, with high rates of recurrence during the first five years, followed by a significant decrease and plateau in recurrence rates after this period. ${ }^{6,7}$ These patients experience more frequent distant recurrences in visceral organs, including the lungs, brain, liver, and less frequently in the bone. ${ }^{8}$ In addition, the survival rate of patients with TNBC decreases after recurrence of the disease compared to $\mathrm{BC}$ patients who test positive for hormone receptors. ${ }^{3,5}$

Prognostic factors and determinants of outcome in patients with TNBC differ significantly from other groups of BC patients. Several epidemiological studies have demonstrated that age and ethnicity are important determinants of outcome in patients with TNBC. ${ }^{9,10}$ Clinicopathological studies have also demonstrated that some clinical characteristics and tumor characteristics are considered important prognostic factors in patients with TNBC. ${ }^{7,11}$ These include tumor size, lymphovascular invasion and distant metastasis. ${ }^{12}$

Survival and outcome among patients with TNBC 
are highly dependent on demographic factors and ethnicity. ${ }^{5,713}$ Thus, understanding prognostic factors in TNBC in each geographical region and ethnic group provides further understanding which will eventually provide a personalized management plan to tailor a multimodality treatment option for a subtype of $\mathrm{BC}$ which has no definite therapeutic target. In addition, data from Iran is scarce and only few studies have reported the clinicopathological characteristics of the disease. ${ }^{11,13,14}$ Considering that TNBC is a unique clinical entity, we aimed to evaluate the clinicopathology of TNBC among women and to determine prognostic factors in this population using data from one of the largest $\mathrm{BC}$ registries in our region.

\section{Materials and Methods Study Population}

This study is part of the Shiraz Breast Cancer Registry (SBCR), which is a tertiary referral cancer center in southern Iran, affiliated with Shiraz University of Medical Sciences. This is the largest BC registry in Iran and includes data from patients with BC from 1995 to the current date. Specifics on the registry have been reported elsewhere. ${ }^{13}$ This study included all patients from the database and patients with a pathologically proven TNBC who had complete clinical, pathological and follow-up data from February 2001 to January 2019. Patients with ductal carcinoma in situ and recurrent BCs were excluded from the study. Furthermore, those with incomplete medical records and those who were lost to follow-up were also excluded.

\section{TNBC Definition}

TNBC was defined as lack of surface expression of ER, PR, and HER2/ErbB2. The status of ER, PR and HER2 was determined by immunohistochemical staining (IHC) and fluorescence in situ hybridization (FISH) at the pathology department of Shiraz University of Medical Sciences. The formalin-fixed paraffin-embedded histological sections were reviewed and the diagnoses were confirmed by two dedicated breast pathologists.

IHC analysis was performed to determine ER/PR status using standard procedures on $4-\mu \mathrm{m}$ sections of paraffinembedded tissues stained with monoclonal antibody for ER and PR. Assessment of ER and PR status was carried out according to the Reiner Score. ER and PR status was considered negative with less than $1 \%$ positive tumor cells. $^{15}$

HER 2 was assessed by means of IHC and/or FISH. IHC was scored on a qualitative scale from 0 to $3+$ based on interpretation of membranous staining intensity, where 0 and $1+$ were classified as negative, $2+$ as borderline, and 3+ as positive. HER2 (++) tissues were re-evaluated by FISH and if the HER2 gene amplification copy-to-CEP17 ratio was greater than 2.0, that sample was considered HER2 positive.

\section{Study Protocol}

Baseline information including age at diagnosis, history of $\mathrm{BC}$ and physical activity; obstetric and gynecological information including age at start of menstruation, age at first pregnancy, number of pregnancies, number of abortions, number of children, duration of breast feeding, oral contraceptive use, hormone replacement therapy, history of benign breast diseases, and age at menopause; tumor characteristics such as size, stage, grade, nodal involvement, invasion status; treatment; and pathology related characteristics including type of surgery, grade of nucleus, tumor necrosis, in situ component in histological evaluation, histopathological subtype and type of management of axillary lymph nodes were registered.

Invasion status was considered positive if present on either biopsy or surgical pathology. All patients were followed according to the registry protocol. ${ }^{13}$

Recurrence in the ipsilateral treated breast and/or chest wall or ipsilateral nodal basin was considered loco-regional recurrence. Any recurrence at a distant site was considered distant metastasis. All study outcomes were evaluated in the last follow-up.

\section{Statistical Analysis}

All statistical analyses were conducted using the Statistical Package for Social Sciences (SPSS Inc., Chicago, Illinois, USA) version 22.0. For comparison of quantitative data with normal distribution between two groups, the independent $t$ test, and for comparison of qualitative data between groups, the chi-square test was used.

Initially, the Kaplan-Meier test was used to evaluate overall survival (OS) and disease-free survival (DFS). DFS was considered as the period from the last day of treatment to confirmation of recurrent disease in the ipsilateral breast, regional, or distant site, and/or death during which the patient was symptom-free. For patients who remained alive and recurrence-free, OS was considered as the period from the last day of treatment to death or the last followup. The logrank test was used to compared OS and DFS between subgroups.

To assess the independent relationship between each variable and survival and recurrence, we used a multivariate Cox regression analysis considering the date of treatment as the start point and the date of event as either death or recurrence as the endpoint. Recurrence was considered any type of local, regional and/or distant metastasis. A stepwise method was used for variable insertion and a $P$ value cutoff entry level of 0.10 was set for variable selection for the Cox regression model.

For evaluation of predictors of recurrence and survival, those with stage $4 \mathrm{BC}$ 's were excluded, as these individuals already have metastatic disease. The OS and DFS were assessed for the whole population and for individuals with 
diagnosis of $\mathrm{BC}$ more than five years separately.

A two-sided $P$ value of less than 0.05 was considered statistically significant.

\section{Results}

During the study period, a total of 6145 women with primary $\mathrm{BC}$ confirmed by pathological examination were included in the SBCR. A total of 523 women were diagnosed with TNBC. The mean age of patients at first diagnosis was $46.52 \pm 11.42$ (ranging from 24 to 81 ) years. Most of the patients were in histological grade III (48.8\%) and the majority of patients had a tumor size between 2 and $5 \mathrm{~cm}$ (66.7\%). Invasive ductal carcinoma and medullary carcinoma were the most common types of BC $(77.7 \%$ and $14.1 \%$, respectively). During our study period, in total, $17.8 \%$ of patients experienced recurrence. Nodal involvement was recorded in one third of patients (35.5\%). Most of the patients $(58.9 \%)$ were treated with breast conserving surgery and auxiliary node dissection was carried out in the majority of patients (62.5\%). The clinical and histopathological characteristics of patients are summarized in Table 1.

Comparison of those with and without recurrence showed that the percentage of individuals with stage 3 and $4 \mathrm{BC}(29.9 \%$ vs. $14.4 \%$ and $7.8 \%$ vs. $0 \%$ for stage 3 and 4 , respectively; $P<0.001)$, invasive ductal carcinoma $(90.7 \%$ vs. $75.6 \% ; P=0.004)$, and nodal involvement $(46.7 \%$ vs. $33.4 \% ; P=0.026$ ) was significantly higher in the group that developed recurrence. Moreover, mastectomy rates (57.3\% vs. $37.8 \% ; P=0.001)$ and axillary node dissection rates $(76.7 \%$ vs. $59.8 \% ; P=0.019)$, were also significantly higher in the group that developed recurrence among TNBC patients. The median (IQR) duration of follow-up was $48(29,74)$ months (Table 2).

The DFS rate was $80.6 \%$ and the mean DFS was 157.76 \pm 9.48 months among patients with TNBC. The OS rate was $90.1 \%$ and the mean OS was $182.73 \pm 3.28$ months (Figure 1).

The Cox regression analysis showed that for overall death, stage 3 BC (compared to stages 0 and 1 as base) showed a higher odds of earlier death (HR: 4.191, $95 \% \mathrm{CI}=1.392-12.621 ; P=0.011)$. Similarly, among individuals who had a diagnosis of $\mathrm{BC}$ for more than five years, stage $3 \mathrm{BC}$ showed higher odds of earlier death (HR: 4.210, 95\% CI = 1.393 - 12.719; P=0.011) (Table 3).

For recurrence, stage 3 BC (HR: $1.044,95 \% \mathrm{CI}=1.209$ - 6.673; $P=0.017$ ) (compared to stages 0 and 1 as base) showed significantly higher odds for developing earlier recurrence. Moreover, those who had invasive ductal carcinoma (compared to other types of BCs) had higher odds for developing earlier recurrence (HR: 3.307, 95\% $\mathrm{CI}=1.191-0.724 ; P=0.012)$. Among those who had a diagnosis of $\mathrm{BC}$ for more than five years, only invasive ductal carcinoma (compared to other types of BC's) showed significantly higher odds of developing earlier
Table 1. Clinicopathological Characteristics of Patients with Triple Negative Breast Cancer*

\begin{tabular}{|c|c|}
\hline Variables & $\begin{array}{l}\text { Triple-Negative Breast } \\
\text { Cancer }(n=523)\end{array}$ \\
\hline Age at diagnosis (Mean $\pm \mathrm{SD}$ ) & $46.52 \pm 11.42$ \\
\hline Age at start of menstruation (Mean $\pm \mathrm{SD}$ ) & $13.33 \pm 1.48$ \\
\hline Age at first pregnancy (Mean \pm SD) & $20.60 \pm 5.16$ \\
\hline Number of pregnancies (Mean \pm SD) & $3.48 \pm 1.98$ \\
\hline Number of abortions (Mean \pm SD) & $1.51 \pm 1.06$ \\
\hline Number of children (Mean \pm SD) & $3.31 \pm 1.80$ \\
\hline $\begin{array}{l}\text { Duration of breast feeding-months (Mean } \pm \\
\text { SD) }\end{array}$ & $58.01 \pm 42.23$ \\
\hline Age at menopause (Mean \pm SD) & $47.25 \pm 4.86$ \\
\hline \multicolumn{2}{|l|}{ Oral contraceptive use, No. (\%) } \\
\hline Yes & $167(54)$ \\
\hline No & $142(46)$ \\
\hline \multicolumn{2}{|l|}{ Hormone replacement therapy, No. (\%) } \\
\hline Yes & $3(1)$ \\
\hline No & $299(99)$ \\
\hline \multicolumn{2}{|l|}{ History of benign breast diseases, No. (\%) } \\
\hline Yes & $11(3.6)$ \\
\hline No & $295(96.4)$ \\
\hline \multicolumn{2}{|l|}{ Family history of breast cancer, No. (\%) } \\
\hline Yes & $78(24.9)$ \\
\hline No & $235(75.1)$ \\
\hline \multicolumn{2}{|l|}{ Physical activity, No. (\%) } \\
\hline Yes & $131(42.1)$ \\
\hline No & $180(57.9)$ \\
\hline \multicolumn{2}{|l|}{ Stage, No. $(\%)^{* *}$} \\
\hline 0 & $8(1.8)$ \\
\hline 1 & $101(22.3)$ \\
\hline 2 & $261(57.6)$ \\
\hline 3 & $77(17)$ \\
\hline 4 & $6(1.3)$ \\
\hline Tumor size $(\mathrm{cm})$ & $3.03 \pm 1.68(0.30-18)$ \\
\hline \multicolumn{2}{|l|}{ Tumor size, No. (\%) } \\
\hline$<2$ & $141(27 \%)$ \\
\hline $2-5$ & $349(66.7 \%)$ \\
\hline$>5$ & $33(6.3 \%)$ \\
\hline \multicolumn{2}{|l|}{ Histological grade, No. (\%) } \\
\hline 1 & $32(8.3)$ \\
\hline II & $166(42.9)$ \\
\hline III & $189(48.8)$ \\
\hline \multicolumn{2}{|l|}{ Pathological type, No. (\%) } \\
\hline Invasive ductal carcinoma & $405(80)$ \\
\hline Medullary carcinoma & $71(14.1)$ \\
\hline Metaplastic carcinoma & $7(1.4)$ \\
\hline Others & $21(4.5)$ \\
\hline \multicolumn{2}{|l|}{$\begin{array}{l}\text { In situ component in histological evaluation, } \\
\text { No. }(\%)\end{array}$} \\
\hline Yes & $217(55.8)$ \\
\hline No & $172(44.2)$ \\
\hline
\end{tabular}


Table 1. Continues

\begin{tabular}{|c|c|}
\hline Variables & $\begin{array}{l}\text { Triple-Negative Breast } \\
\text { Cancer }(n=523)\end{array}$ \\
\hline \multicolumn{2}{|l|}{ Tumor necrosis, No. $(\%)$} \\
\hline Yes & $285(69.7)$ \\
\hline No & $124(30.3)$ \\
\hline \multicolumn{2}{|l|}{ Grade of nucleus, No. (\%) } \\
\hline 1 & $9(8.2)$ \\
\hline 2 & $36(32.7)$ \\
\hline 3 & $65(59.1)$ \\
\hline \multicolumn{2}{|l|}{ Lymphovascular invasion, No. (\%) } \\
\hline Yes & $164(36.4)$ \\
\hline No & $286(63.6)$ \\
\hline \multicolumn{2}{|l|}{ Perineural invasion, No. (\%) } \\
\hline Yes & $23(5.1)$ \\
\hline No & $427(94.9)$ \\
\hline \multicolumn{2}{|l|}{ Nodal involvement, No. (\%) } \\
\hline Yes & $184(35.3)$ \\
\hline No & $337(64.7)$ \\
\hline \multicolumn{2}{|l|}{ Number of involved lymph nodes, No. (\%) } \\
\hline 0 & $337(64.7)$ \\
\hline $1-3$ & $106(20.3)$ \\
\hline $4-9$ & $46(8.8)$ \\
\hline$\geq 10$ & $32(6.1)$ \\
\hline \multicolumn{2}{|l|}{ Operation, No. (\%) } \\
\hline Breast conserving therapy & $310(59.4)$ \\
\hline Mastectomy & $212(40.6)$ \\
\hline \multicolumn{2}{|l|}{ Axillary management, No. (\%) } \\
\hline Sentinel lymph node biopsy & $148(29.1)$ \\
\hline Axillary node dissection & $316(62.2)$ \\
\hline $\begin{array}{l}\text { Sentinel lymph node biopsy + axillary node } \\
\text { dissection }\end{array}$ & $44(8.7)$ \\
\hline \multicolumn{2}{|l|}{ Duration of follow-up (months) } \\
\hline Mean \pm SD & $53.25 \pm 32.29$ \\
\hline Median (IQR) & $48(29,74)$ \\
\hline \multicolumn{2}{|l|}{ Recurrence, No. (\%) } \\
\hline Yes & $90(17.2 \%)$ \\
\hline No & $433(82.8 \%)$ \\
\hline
\end{tabular}

"All plus-minus values are means and standard deviations, unless stated otherwise.

${ }^{* *}$ Staging was defined according to the TNM staging system.

recurrence (HR: 1.147, 95\% CI =1.130-8.770; $\mathrm{P}=0.028)$ (Table 4 and Figure 2).

\section{Discussion}

In this study, we investigated the determinants of prognosis in a large series of women with TNBC. In our univariate analysis, we found that those who developed recurrence had a higher rate of individuals with higher stages, more individuals with invasive ductal carcinomas (in comparison to other subtypes), more lymphovascular and perineural invasion, more involved lymph nodes, higher rates of breast conserving surgery, and higher rates of axillary node dissection compared to other axillary management modalities.

In our Cox regression analysis, we found that regarding death, stage was a predictor of earlier death and regarding recurrence, stage and histopathological subtype were significant determinants of earlier recurrence. These findings are consistent with previous reports from other ethnic groups. ${ }^{16-22}$

In our series, lymphovascular and perineural invasion were found to be significantly higher among patients with TNBC who showed recurrence. Previously, lymphovascular invasion was shown to be associated with increased risk of recurrence in patients who either had breast conservation therapy or mastectomy. ${ }^{23}$ Lymphovascular invasion has been further associated with worse BC-specific survival and distant metastasis-free survival. ${ }^{24}$ Moreover, we found that about $40 \%$ of the patients with TNBC in our series had lymphovascular invasion which is high compared to previous series. ${ }^{16,22-24}$

Various studies have addressed prognostic factors in TNBC patients in different ethnic groups. Rakha et $\mathrm{al}^{7}$ studied prognostic factors among a sample of TNBC patients from the UK. In their report, among the total 1726 cases of invasive breast carcinomas whom they studied, 282 were TNBC's. They found that nodal status, tumor size, and androgen receptor expression were the most important prognostic factors. We found no association between prognosis and tumor size among our TNBC patients. They also demonstrated that in the lymph node-negative group, basal phenotype was the sole marker that showed prognostic value whereas other specifics, including patients' age, tumor size, and androgen receptor expression, were not significant predictors. ${ }^{7}$ In our multivariate model, we only found the stage of cancer to be a predictor of survival and both stage and histopathological subtype to be predictors for recurrence. The different findings could be attributed to multiple factors: first, the different variables which were included in our regression models, as the mentioned study mostly focused on molecular determinants. Moreover, the mentioned study had a relatively small sample size (compared to that of our study), which may have affected the results of the regression analysis, although this is expected considering the overall low number of patients with TNBC.

Recently, Kashi et $\mathrm{al}^{22}$ reported survival rates and the determinants of outcome in a series of patients with BC. They evaluated 1910 BC patients, among whom 180 (9.4\%) patients had TNBC. They reported that age $(\geq 40$ years), grade and stage III at first diagnosis (compared to grade and stage 1 ), and visceral recurrence were significant predictors of outcome. ${ }^{22}$

In another study, Mirzania et $\mathrm{al}^{14}$ evaluated a total of 267 
Table 2. Comparison of Clinicopathological Characteristics of Patients with Triple-Negative Breast Cancer with and Without Recurrence*

\begin{tabular}{|c|c|c|c|c|c|}
\hline Variables & HR for Death & HR for Recurrence & $\begin{array}{l}\text { Recurrence } \\
\qquad(\mathbf{n}=75)\end{array}$ & $\begin{array}{l}\text { No Recurrence } \\
\quad(n=448)\end{array}$ & $P$ value ${ }^{\star \star}$ \\
\hline Age at diagnosis & $1.019(0.996-1.043)$ & $1.007(0.989-1.024)$ & $45.44 \pm 12.32$ & $46.71 \pm 11.27$ & 0.375 \\
\hline Age at start of menstruation & NA & $1.020(0.773-1.346)$ & $13.35 \pm 1.43$ & $13.33 \pm 1.50$ & 0.956 \\
\hline Age at first pregnancy & NA & $0.950(0.874-1.033)$ & $20.69 \pm 5.25$ & $20.72 \pm 5.26$ & 0.223 \\
\hline Number of pregnancies & NA & $1.111(0.927-1.332)$ & $4.04 \pm 2.35$ & $3.43 \pm 1.95$ & 0.147 \\
\hline Number of abortions & NA & $0.713(0.245-2.073)$ & $1.25 \pm .46$ & $1.53 \pm 1.10$ & 0.476 \\
\hline Number of children & NA & $1.129(0.925-1.378)$ & $3.29 \pm 1.81$ & $3.26 \pm 1.77$ & 0.140 \\
\hline Duration of breast feeding- months & NA & $0.998(0.988-1.008)$ & $56.38 \pm 44.27$ & $58.17 \pm 42.23$ & 0.844 \\
\hline Age at menopause & $\mathrm{NA}$ & $0.974(0.870-1.090)$ & $47.24 \pm 4.86$ & $47.28 \pm 4.90$ & 0.844 \\
\hline \multicolumn{6}{|l|}{ OCP use } \\
\hline Yes & NA (no death) & $0.752(0.332-1.704)$ & $11(44.0)$ & $156(54.9)$ & 0.293 \\
\hline No (ref) & - & & $14(56.0)$ & $12(45.1)$ & - \\
\hline \multicolumn{6}{|l|}{ Hormone replacement therapy } \\
\hline Yes & NA (no death) & NA (no death) & $0(0)$ & $3(1.1)$ & $>0.999$ \\
\hline No (ref) & - & & $25(100)$ & $274(98.9)$ & - \\
\hline \multicolumn{6}{|l|}{ History of benign breast diseases } \\
\hline Yes & NA (no death) & $\begin{array}{c}1.962(0.251- \\
15.362)\end{array}$ & $1(3.8)$ & $10(3.6)$ & $>0.999$ \\
\hline No & - & & $25(96.2)$ & $270(96.4)$ & - \\
\hline \multicolumn{6}{|l|}{ Family history of breast cancer } \\
\hline Yes & NA (no death) & $0.807(0.317-2.057)$ & $6(23.1)$ & $72(25.1)$ & 0.820 \\
\hline No & - & & $20(76.9)$ & $215(74.9)$ & - \\
\hline \multicolumn{6}{|l|}{ Physical activity } \\
\hline Yes & NA (no death) & $0.904(0.373-2.196)$ & $7(26.9)$ & $124(43.5)$ & 0.101 \\
\hline No & - & - & $19(73.1)$ & $161(56.5)$ & - \\
\hline \multicolumn{6}{|l|}{ Stage categorized } \\
\hline 0 and 1 & - & - & $11(19)$ & $98(25.2)$ & 0.011 \\
\hline 2 & $1.783(0.672-4.729)$ & $1.117(0.558-2.236)$ & $29(50)$ & $232(59.6)$ & - \\
\hline 3 & $\begin{array}{c}4.694(1.706- \\
12.919)\end{array}$ & $2.571(1.213-5.450)$ & $18(31)$ & $59(15.2)$ & - \\
\hline Tumor size $(\mathrm{cm})$ & $1.178(1.052-1.319)$ & $1.117(0.973-1.283)$ & $3.31 \pm 2.51$ & $3.01 \pm 1.50$ & 0.337 \\
\hline \multicolumn{6}{|l|}{ Tumor size } \\
\hline$<2$ (ref) & - & - & $21(28)$ & $120(26.8)$ & 0.671 \\
\hline $2-5$ & $1.148(0.595-2.218)$ & $1.034(0.619-1.730)$ & $51(68)$ & $298(66.5)$ & - \\
\hline$>5$ & $1.842(0.649-5.231)$ & $1.420(0.420-4.805)$ & $3(4)$ & $30(6.7)$ & - \\
\hline \multicolumn{6}{|l|}{ Histological grade } \\
\hline I (ref) & - & - & $6(9.7)$ & $26(8)$ & 0.791 \\
\hline II & $0.795(0.324-1.954)$ & $.983(0.401-2.409)$ & $28(45.2)$ & $138(42.5)$ & - \\
\hline III & $0.372(0.140-0.993)$ & $1.305(0.536-3.181)$ & $28(45.2)$ & $161(49.5)$ & - \\
\hline \multicolumn{6}{|l|}{ Pathological type } \\
\hline Invasive ductal carcinoma & $2.008(0.904-4.459)$ & $0.718(0.325-1.583)$ & $68(90.7)$ & $337(75.6)$ & 0.004 \\
\hline Others (ref) & - & - & $7(9.3)$ & $109(24.4)$ & - \\
\hline \multicolumn{6}{|l|}{ In situ component in pathology } \\
\hline Yes & $1.039(0.565-1.908)$ & $1.293(0.788-2.122)$ & $36(55.4)$ & $181(55.9)$ & $>0.999$ \\
\hline No (ref) & - & - & $29(44.6)$ & $143(44.1)$ & - \\
\hline \multicolumn{6}{|l|}{ Tumor necrosis } \\
\hline Yes & $0.621(0.332-1.163)$ & $1.109(0.647-1.901)$ & $42(67.7)$ & $243(70)$ & 0.718 \\
\hline No (ref) & - & - & $20(32.3)$ & $104(30)$ & - \\
\hline \multicolumn{6}{|l|}{ Grade of nucleus } \\
\hline 1 (ref) & - & - & $3(17.6)$ & $6(6.5)$ & 0.256 \\
\hline 2 & $0.232(0.048-1.126)$ & $1.522(0.332-6.965)$ & $4(23.5)$ & $32(34.4)$ & - \\
\hline 3 & $0.125(0.025-0.620)$ & $2.127(0.560-8.072)$ & $10(58.8)$ & $55(59.1)$ & - \\
\hline \multicolumn{6}{|l|}{ Lymphovascular invasion } \\
\hline Yes (ref) & $1.165(0.651-2.086)$ & $1.162(0.704-1.920)$ & $27(39.1)$ & $137(36)$ & 0.614 \\
\hline No & - & - & $42(60.9)$ & $244(64)$ & - \\
\hline \multicolumn{6}{|l|}{ Perineural invasion } \\
\hline Yes (ref) & $0.419(0.058-3.039)$ & $2.341(0.720-7.613)$ & $3(4.3)$ & $20(5.2)$ & $>0.999$ \\
\hline No & - & - & $66(95.7)$ & $361(94.8)$ & - \\
\hline \multicolumn{6}{|l|}{ Nodal involvement } \\
\hline Yes (ref) & $2.629(1.509-4.577)$ & $1.214(0.763-1.931)$ & $35(46.7)$ & $149(33.4)$ & 0.026 \\
\hline No & - & - & $40(53.3)$ & $297(66.6)$ & - \\
\hline Number of involved lymph nodes & & & & & \\
\hline
\end{tabular}


Table 2. Continues

\begin{tabular}{|c|c|c|c|c|c|}
\hline Variables & HR for Death & HR for Recurrence & $\begin{array}{c}\text { Recurrence } \\
(n=75)\end{array}$ & $\begin{array}{c}\text { No Recurrence } \\
(n=448)\end{array}$ & $P$ value ${ }^{\star *}$ \\
\hline 0 (ref) & - & - & $40(53.3)$ & $297(66.6)$ & 0.056 \\
\hline $1-3$ & $2.125(1.087-4.154)$ & $0.946(0.532-1.683)$ & $17(22.7)$ & $89(20)$ & - \\
\hline $4-9$ & $2.966(1.320-6.664)$ & $1.418(0.729-2.760)$ & $12(16)$ & $34(7.6)$ & - \\
\hline$\geq 10$ & $4.018(1.714-9.417)$ & $2.711(1.105-6.650)$ & $6(8)$ & $26(5.8)$ & - \\
\hline \multicolumn{6}{|l|}{ Operation } \\
\hline Breast conserving therapy (ref) & - & - & $32(42.7)$ & $278(62.2)$ & 0.001 \\
\hline Mastectomy & $2.379(1.348-4.199)$ & $0.678(0.424-1.087)$ & $43(57.3)$ & $169(37.8)$ & - \\
\hline \multicolumn{6}{|l|}{ Axillary Management } \\
\hline Sentinel lymph node biopsy & $0.355(0.150-0.837)$ & $1.219(0.630-2.360)$ & $12(16.4)$ & $136(31.3)$ & 0.019 \\
\hline Axillary node dissection (ref) & - & - & $56(76.7)$ & $260(59.8)$ & - \\
\hline $\begin{array}{l}\text { Sentinel lymph node biopsy + axillary } \\
\text { node dissection }\end{array}$ & $0.583(0.180-1.887)$ & $1.367(0.542-3.449)$ & $5(6.8)$ & $39(9)$ & - \\
\hline Duration of follow-up, median (IQR) & - & - & $30(21.75,39.50)$ & $56.05(31,76)$ & $<0.001$ \\
\hline
\end{tabular}

"All plus-minus values are means and standard deviations, unless stated otherwise. Staging was defined according to the TNM staging system.

${ }^{* *} P$ value of chi-square test.
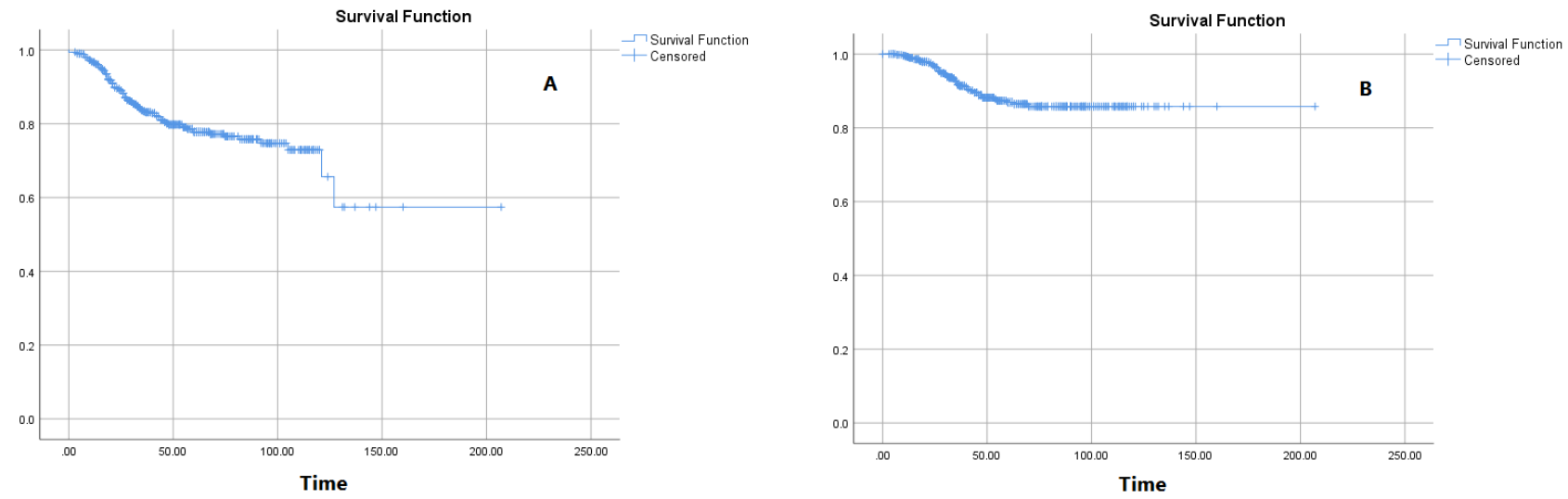

Figure 1. The Kaplan-Meier Plot for Overall Survival and Disease-Free Survival among Patients with Triple Negative Breast Cancer (TNBC). Panel A shows the disease-free survival plot by months of follow-up and panel B shows the overall survival plot by months of follow-up.
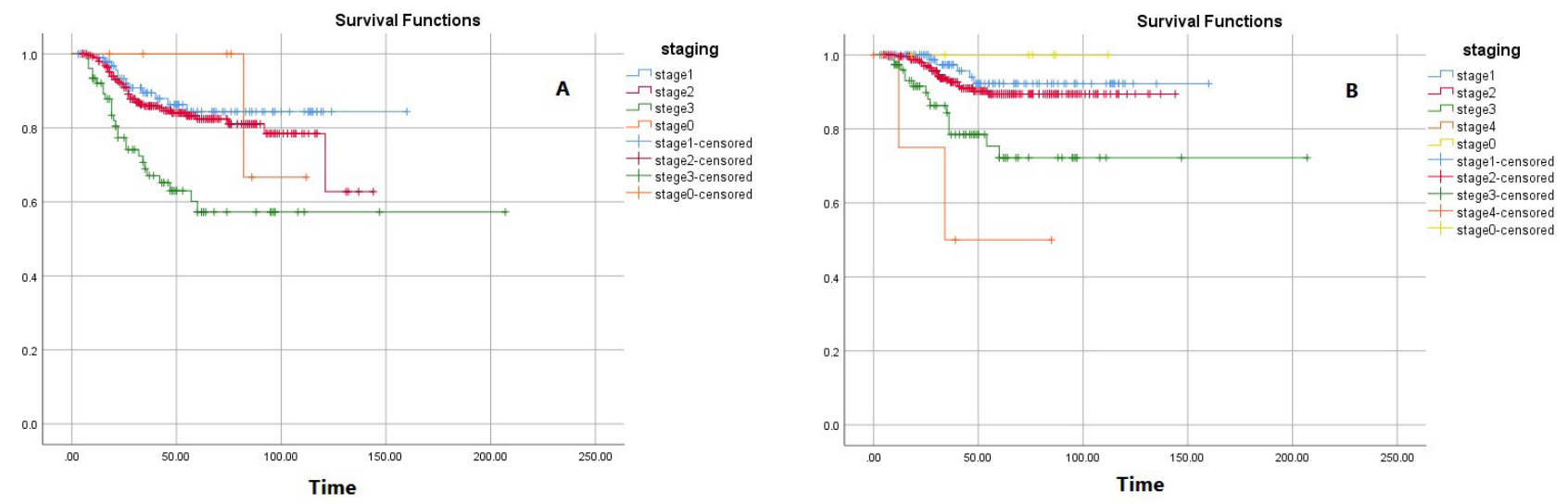

Figure 2. Overall Survival and Disease-Free Survival by Stage. Panel A shows disease-free survival by stage (excluding stage 4) and panel B shows overall survival by stage.

patients with BC, among whom 60 had TNBC (22.5\%). They found that subtype on pathological evaluation, metastases to bone, clinical stage, involvement of lymph nodes and size of tumor were significant predictors of outcome. ${ }^{14}$ The results of the aforementioned study were similar to ours.

Accordingly, Agrawal et $\mathrm{al}^{25}$ found that TNBC more often occurs at younger ages; furthermore, these tumors present with a more aggressive clinicopathology compared to non-TNBC patients as they showed a worse prognosis in terms of DFS and OS. When categorized according to stage, in stage III, patients with TNBC showed a worse survival compared to the control group of non-TNBC patients. However, in other stages, these groups were not 
Table 3. Cox Regression for Determining Predictors of Survival among Patients with Triple-Negative Breast Cancer

\begin{tabular}{|c|c|c|c|}
\hline Variables & Hazards Ratio & $95 \% \mathrm{Cl}$ & $P$ Value \\
\hline \multicolumn{4}{|c|}{ Overall } \\
\hline Age at diagnosis & 1.018 & $0.992-1.045$ & 0.181 \\
\hline Tumor size & 1.055 & $0.857-1.298$ & 0.616 \\
\hline \multicolumn{4}{|l|}{ Stage* } \\
\hline $0 \& 1$ & - & - & - \\
\hline 2 & 1.619 & $0.579-4.521$ & 0.358 \\
\hline 3 & 4.191 & $1.392-12.621$ & 0.011 \\
\hline \multicolumn{4}{|c|}{ Patient with $>5$ Years from Diagnosis } \\
\hline Age at diagnosis & 1.018 & 0.992-1.045 & 0.060 \\
\hline Tumor size & 1.042 & $0.854-1.284$ & 0.701 \\
\hline \multicolumn{4}{|l|}{ Stage* } \\
\hline $0 \& 1$ & - & - & - \\
\hline 2 & 1.619 & $0.581-4.512$ & 0.357 \\
\hline 3 & 4.210 & $1.393-12.719$ & 0.011 \\
\hline
\end{tabular}

*Staging was defined according to the TNM staging system; stage 4 breast cancer was excluded from this model.

Table 4. Cox Regression for Determining Predictors of Recurrence Among Patients with Triple-Negative Breast Cancer

\begin{tabular}{|c|c|c|c|}
\hline Variables & Hazards Ratio & $95 \% \mathrm{Cl}$ & $P$ Value \\
\hline \multicolumn{4}{|c|}{ Overall } \\
\hline Age at diagnosis & 0.983 & $0.959-1.007$ & 0.172 \\
\hline Tumor size & 0.888 & $0.724-1.089$ & 0.252 \\
\hline \multicolumn{4}{|l|}{ Stage* } \\
\hline $0 \& 1$ & - & - & - \\
\hline 2 & 1.278 & $0.594-2.750$ & 0.530 \\
\hline 3 & 2.841 & $1.209-6.673$ & 0.017 \\
\hline \multicolumn{4}{|l|}{ Pathological type } \\
\hline $\begin{array}{l}\text { Invasive ductal } \\
\text { carcinoma }\end{array}$ & 3.307 & $1.191-9.181$ & 0.022 \\
\hline Others & - & - & - \\
\hline \multicolumn{4}{|c|}{ Patient with $>5$ Years from Diagnosis } \\
\hline Age at diagnosis & 0.983 & $0.958-1.009$ & 0.197 \\
\hline Tumor size & 0.897 & $0.720-1.117$ & 0.331 \\
\hline \multicolumn{4}{|l|}{ Stage* } \\
\hline $0 \& 1$ & - & - & - \\
\hline 2 & 1.084 & $0.494-2.379$ & 0.841 \\
\hline 3 & 2.282 & $0.922-5.644$ & 0.075 \\
\hline \multicolumn{4}{|l|}{ Pathological type } \\
\hline $\begin{array}{l}\text { Invasive ductal } \\
\text { carcinoma }\end{array}$ & 3.148 & $1.130-8.770$ & 0.028 \\
\hline Others & - & - & - \\
\hline
\end{tabular}

*Staging was defined according to the TNM staging system; stage 4 breast cancer was excluded from this model.

different. ${ }^{25}$ Conversely, Kim et a ${ }^{26}$ found that patients with TNBC have similar results with regard to loco-regional recurrence using breast conserving surgery compared to those without TNBC. Consequently, they concluded that breast conserving surgery is a good treatment choice among these patients. ${ }^{26}$

In a previous comprehensive report, the authors found age at diagnosis, number of dissected lymph nodes, number of involved lymph nodes, in situ component, grade, tumor necrosis, history of breast disease, smoking, type of axillary management, radiotherapy and stage of cancer to be involved in recurrence among BC patients (not specific to TNBC) using a machine learning algorithm. ${ }^{27}$ Although a different statistical approach was used, these findings were different when compared to patients with TNBC as we found only stage and histopathological subtype to be significant predictors of recurrence in this population. This difference in findings could be attributed to the different subtype of BC which was studied, and further studies are needed to directly compare the determinants of outcome between different subtypes of BC. Another point is that some previous studies had entered factors such as tumor size as a categorical variable in their multivariable models and perhaps these factors are significant for prediction of prognosis at a specific cut-off point; thus, they did not appear as significant in our final model.

Our findings indicate that patients with TNBC who present with a higher stage would perhaps benefit from earlier screening programs for evaluation of recurrence in their follow-up visits as stage is a predictor of earlier recurrence in this specific population. This could also be considered for patients who show invasion (lymphovascular or perineural) on their assessment.

This study was not without limitations. We did not include demographic and social variables in our analysis as they had a lot of missing data, although the role of demographic/ethnical and social factors are well known in determining the outcome of patients with TNBC. ${ }^{16}$ Although the rates of TNBC are low by nature, we used data from one of the largest databases to overcome this issue; however, some subgroups did still have low numbers of individuals. Due to the rarity of TNBC patients, compared to the whole number of patients with $\mathrm{BC}$, we included all individuals in our regression models. Some patients who were included in our models and who have been recently diagnosed may not have had the chance to present outcomes such as death or recurrence and may have caused some bias in our results. Some of the total 6145 BC patients that were included in our current report may have had missing data regarding HER2 status, ER or PR receptor expression status; thus, the exact rate of TNBC among our total population is not measurable from the current report. For recurrence, we classified histopathology into two groups of IDC and "others". This classification was mainly done due to the small number of patients who would classify as "others", and those with IDC may not necessarily have had better conditions regarding recurrence compared to all subtypes of BC's as shown in our multivariate analysis. Furthermore, although we separated those with stage four BC, to eliminate the 
competing risk of metastasis from death, from the Cox regression analysis of survival, we could have used a competing risk survival analysis ${ }^{28,29}$ to assess and analyze the data.

Overall, this is among the largest studies in the literature that determined survival and recurrence in TNBC and is the largest study in our region to evaluate TNBC patients.

In conclusion, BC stage plays a significant role in both earlier recurrence and earlier mortality among patients with TNBC.

\section{Authors' Contribution}

MA, ST, VZ and AT aided in the conceptualization, design, and critical revision of the final manuscript. PA and PA aided in design, data analysis and preparation of manuscript. AMJA, SMH, and AA aided in data gathering and preparation of final manuscript. All authors have read and approved the manuscript.

\section{Conflict of Interest Disclosure}

The Authors have no conflict of interest to declare.

\section{Ethical Statement}

The study protocol was approved by the Institutional Review Board of Shiraz University of Medical Sciences, Shiraz, Iran. All study protocols followed guidelines stated in the Declaration of Helsinki.

\section{Acknowledgements}

The authors would like to thank all the personnel at the Shiraz Breast Cancer Registry who aided in the gathering of the data and all patients and their families who kindly took part in this study.

\section{References}

1. Foulkes WD, Smith IE, Reis-Filho JS. Triple-negative breast cancer. N Engl J Med. 2010;363(20):1938-48. doi: 10.1056/ NEJMra1001389.

2. Winnike JH, Stewart DA, Pathmasiri WW, McRitchie SL, Sumner SJ. Stable isotope-resolved metabolomic differences between hormone-responsive and triple-negative breast cancer cell lines. Int J Breast Cancer. 2018;2018:2063540. doi: 10.1155/2018/2063540. eCollection 2018.

3. Temian DC, Pop LA, Irimie Al, Berindan-Neagoe I. The epigenetics of triple-negative and basal-like breast cancer: current knowledge. J Breast Cancer. 2018;21(3):233-243. doi: 10.4048/jbc.2018.21.e41.

4. Plasilova ML, Hayse B, Killelea BK, Horowitz NR, Chagpar AB, Lannin DR. Features of triple-negative breast cancer: Analysis of 38,813 cases from the national cancer database. Medicine. 2016;95(35):e4614. doi: 10.1097/MD.0000000000004614.

5. Reddy SM, Barcenas $\mathrm{CH}$, Sinha AK, Hsu L, Moulder SL, Tripathy D, et al. Long-term survival outcomes of triplereceptor negative breast cancer survivors who are disease free at 5 years and relationship with low hormone receptor positivity. Br J Cancer. 2018;118(1):17-23. doi: 10.1038/ bjc.2017.379.

6. Hudis CA, Gianni L. Triple-negative breast cancer: an unmet medical need. The oncologist. 2011;16 Suppl 1:1-11. doi: 10.1634/theoncologist.2011-S1-01.

7. Rakha EA, El-Sayed ME, Green AR, Lee AH, Robertson JF, Ellis IO. Prognostic markers in triple-negative breast cancer. Cancer. 2007;109(1):25-32. doi: 10.1002/cncr.22381.

8. James M, Dixit A, Robinson B, Frampton C, Davey V. Outcomes for Patients with Non-metastatic Triple-negative Breast Cancer in New Zealand. Clin Oncol. 2019;31(1):1724. doi: 10.1016/j.clon.2018.09.006.

9. Wei XQ, Li X, Xin XJ, Tong ZS, Zhang S. Clinical features and survival analysis of very young $($ age $<35)$ breast cancer patients. Asian Pac J Cancer Prev. 2013;14(10):5949-52. doi: 10.7314/apjcp.2013.14.10.5949.

10. Turkoz FP, Solak M, Petekkaya I, Keskin O, Kertmen N, Sarici F, et al. The prognostic impact of obesity on molecular subtypes of breast cancer in premenopausal women. J BUON. 2013;18(2):335-41.

11. Abdollahi A, Etemadi M. Pathological Characteristics of TripleNegative Breast Cancer at Main Referral Teaching Hospital, April 2014 to April 2015, Tehran, Iran. Int J Hematol Oncol Stem Cell Res. 2016;10(4):200-205.

12. Mohammed ZM, McMillan DC, Edwards J, Mallon E, Doughty JC, Orange C, et al. The relationship between lymphovascular invasion and angiogenesis, hormone receptors, cell proliferation and survival in patients with primary operable invasive ductal breast cancer. BMC Clin Pathol. 2013;13(1):31 . doi: 10.1186/1472-6890-13-31.

13. Talei A, Tahmasebi S, Akrami M, Zangouri V, Rezaianzadeh A, Arasteh P, et al. The Shiraz Breast Cancer Registry (SBCR): study design and primary reports. Per Med. 2018;15(6):471479. doi: 10.2217/pme-2018-0047.

14. Mirzania M, Safaee SR, Shahi F, Jahanzad I, Zahedi G, Mehdizadeh R. Treatment Outcomes and Clinicopathologic Characteristics of Triple-Negative Breast Cancer: A Report from Cancer Institute of Iran. Int J Hematol Oncol Stem Cell Res. 2017;11(1):37-42.

15. Hammond ME, Hayes DF, Dowsett M, Allred DC, Hagerty KL, Badve S, et al. American Society of Clinical Oncology/College Of American Pathologists guideline recommendations for immunohistochemical testing of estrogen and progesterone receptors in breast cancer. J Clin Oncol. 2010;28(16):278495. doi: 10.1200/JCO.2009.25.6529.

16. Thomas K, Shiao J, Rao R, Minhajuddin A, Spangler A, Leitch $\mathrm{M}$, et al. Constructing a Clinicopathologic Prognostic Model for Triple-Negative Breast Cancer. AJHO. 2017;13(1):11-21.

17. Lin C, Chien SY, Kuo SJ, Chen LS, Chen ST, Lai HW, et al. A 10-year follow-up of triple-negative breast cancer patients in Taiwan. Jpn J Clin Oncol. 2012;42(3):161-7. doi: 10.1093/ jico/hyr196.

18. You JY, Lee HY, Woo SU, Park KH, Lee ES, Bae JW. Are there the specific prognostic factors for triple-negative subtype of early breast cancers (pT1-2NOM0)? Korean J Clin Oncol. 2011;7(2):12-21. doi: 10.14216/kjco.11014.

19. Ishikawa Y, Horiguchi J, Toya $H$, Nakajima H, Hayashi M, Tagaya $\mathrm{N}$, et al. Triple-negative breast cancer: histological subtypes and immunohistochemical and clinicopathological features. Cancer Sci. 2011;102(3):656-62. doi: 10.1111/j.13497006.2011.01858.x

20. Qiu J, Xue X, Hu C, Xu H, Kou D, Li R, et al. Comparison of Clinicopathological Features and Prognosis in TripleNegative and Non-Triple Negative Breast Cancer. J Cancer. 2016;7(2):167-73. doi: 10.7150/jca.10944.

21. Hernandez-Aya LF, Chavez-Macgregor M, Lei X, MericBernstam F, Buchholz TA, Hsu L, et al. Nodal status and clinical outcomes in a large cohort of patients with triplenegative breast cancer. J Clin Oncol. 2011;29(19):2628-34. doi: 10.1200/JCO.2010.32.1877.

22. Kashi ASY, Yazdanfar S, Akbari M-E, Rakhsha A. Triple negative breast cancer in iranian women: Clinical profile and survival study. Int J Cancer Manag. 2017;10(8). doi: 10.5812/ ijcm.10471.

23. Ahn KJ, Park J, Choi Y. Lymphovascular invasion as a negative prognostic factor for triple-negative breast cancer after surgery. Radiat Oncol J. 2017;35(4):332-9. doi: 10.3857/ roj.2017.00416.

24. Rakha EA, Martin S, Lee AH, Morgan D, Pharoah PD, Hodi Z, et al. The prognostic significance of lymphovascular invasion in invasive breast carcinoma. Cancer. 2012;118(15):3670-80. 
doi: 10.1002/cncr.26711.

25. Agarwal G, Nanda G, Lal P, Mishra A, Agarwal A, Agrawal $\mathrm{V}$, et al. Outcomes of Triple-Negative Breast Cancers (TNBC) Compared with Non-TNBC: Does the Survival Vary for All Stages? World J Surg. 2016;40(6):1362-72. doi: 10.1007/ s00268-016-3422-4.

26. Kim S, Park HS, Kim JY, Ryu J, Park S, Kim SI. Comparisons of Oncologic Outcomes between Triple-Negative Breast Cancer (TNBC) and Non-TNBC among Patients Treated with BreastConserving Therapy. Yonsei Med J. 2016;57(5):1192-8. doi: 10.3349/ymj.2016.57.5.1192.
27. Akrami M, Arasteh P, Eghbali T, Shahraki HR, Tahmasebi S, Zangouri $\mathrm{V}$, et al. Introducing novel and comprehensive models for predicting recurrence in breast cancer using the group LASSO approach: are estimates of early and late recurrence different?. World J Surg Oncol. 2018;16(1):185. doi: 10.1186/s12957-018-1489-0.

28. Lunn M, McNeil D. Applying Cox regression to competing risks. Biometrics. 1995:524-32. doi: 10.2307/2532940.

29. Fine JP, Gray RJ. A proportional hazards model for the subdistribution of a competing risk. J Am Stat Assoc. 1999;94(446):496-509.

(c) (1) 2021 The Author(s). This is an open-access article distributed under the terms of the Creative Commons Attribution License (http://creativecommons. org/licenses/by/4.0), which permits unrestricted use, distribution, and reproduction in any medium, provided the original work is properly cited. 